\title{
Pneumonitis and pneumonia after aspiration
}

\author{
Young Gon Son, Jungho Shin, Ho Geol Ryu \\ Department of Anesthesiology and Pain Medicine, Seoul National University College of Medicine, Seoul National University Hospital, \\ Seoul, Korea
}

\begin{abstract}
Aspiration pneumonitis and aspiration pneumonia are clinical syndromes caused by aspiration. These conditions are clinically significant due to their high morbidity and mortality. However, aspiration as a preceding event are often unwitnessed, particularly in cases of asymptomatic or silent aspiration. Furthermore, despite the difference in treatment approaches for managing aspiration pneumonitis and aspiration pneumonia, these two disease entities are often difficult to discriminate from one another, resulting in inappropriate treatment. The use of unclear terminologies hinders the comparability among different studies, making it difficult to produce evidence-based conclusions and practical guidelines. We reviewed the most recent studies to define aspiration, aspiration pneumonitis, and aspiration pneumonia, and to further assess these conditions in terms of incidence and epidemiology, pathophysiology, risk factors, diagnosis, management and treatment, and prevention.
\end{abstract}

Keywords: Pneumonia, Aspiration; Pneumonitis.

This is an Open Access article distributed under the terms of the Creative Commons Attribution Non-Commercial License (http://creativecommons.org/licenses/by-nc/3.0/) which permits unrestricted non-commercial use, distribution, and reproduction in any medium, provided the original work is properly cited.

\section{DEFINITION}

Aspiration simply means to draw in or out by means of suction. In patient care, the term aspiration is often used to describe the inflow of material from the oral cavity or upper gastrointestinal tract into the lungs through the larynx. The term itself does not reflect the nature of the material or the specific outcome of the event [1]. The material that can be aspirated varies and includes saliva, nasopharyngeal secretions, bacteria, liquids, toxic substances, food, or gastric contents. The outcome of the event also varies widely; it can remain within the spectrum of normal physiology or result in very severe conditions such as acute respiratory distress syndrome (ARDS) [2,3]. Most the clinical outcomes are outlined in Table 1. These manifestations of aspiration are cate- gorized based on three key characteristics, including the infectiousness of the inoculum, volume of the inoculum, and acuity of the onset of the clinical syndrome [4]. Important manifestations that induce sudden changes in the patients' conditions and are troublesome for the clinicians, especially for the intensive care unit (ICU) health providers, are aspiration pneumonitis (chemical pneumonitis) and aspiration pneumonia (infectious process secondary to an aspiration event) caused by macroaspiration. However, aspiration can be silent (unwitnessed), and it is difficult to distinguish between these two manifestations [2,5].

Aspiration pneumonitis is defined as a condition that shows immediate hypoxemia, fever, tachycardia, and abnormalities on chest radiograph, which is caused by macroaspiration of noxious liquids. The noxious fluids are mostly sterile gastric contents; although they can be

Received: 2017. February. 11. - Revised: 2017. February. 19. - Accepted: 2017. February. 20.

Corresponding Author: Ho Geol Ryu, Department of Anesthesiology and Pain Medicine, Seoul National University Hospital, Seoul National University College of Medicine, 101 Daehak-ro, Jongno-gu, Seoul, Korea, 110-744

Tel: +82-2-2072-2065 Fax: 82-2-747-5639 E-mail: hogeol@gmail.com

Copyright(c) 2017 Journal of Dental Anesthesia and Pain Medicine 
Table 1. Aspiration syndromes

\begin{tabular}{llll}
\hline & Infectious inoculum & Acuity of onset & Volume \\
\hline Airway syndromes & No & Chronic & Micro \\
Chronic cough & No & Acute or subacute & Micro \\
Exacerbation of asthma/bronchospasm & No & Chronic & Micro \\
Bronchiolitis obliterans in lung transplantation & & & Micro \\
Lung parenchymal syndromes & No & Chronic & Macro \\
Exacerbation of fibrotic lung disease & No & Acute & Micro \\
Aspiration pneumonitis & & & Variable \\
Bacterial pneumonia & Yes & Acute & Micro \\
Community acquired & Yes & Acute & Macro \\
Hospital acquired & Yes & Acute & Yes \\
Ventilator associated & & & \\
Aspiration pneumonia & & & \\
\hline
\end{tabular}

also bile or other agents introduced through the stomach [4]. In an animal model, the pathophysiology of chemical pneumonitis has been suggested to be distinguishable from subclinical aspiration based on the $\mathrm{pH}$ and volume of the gastric material. To induce severe inflammation in the experiment using human gastric secretions and rabbit lungs, a pH below 2.4 was required [6]. In a dog model with induced chemical pneumonitis, more than 2 $\mathrm{ml}$ of hydrochloric acid solution per kilogram were required to induce a clinical syndrome $[7,8]$.

Aspiration pneumonia generally implies acute lung infection that occurs after aspiration of oropharyngeal or upper gastrointestinal contents in large volumes. The aspirated contents are often not acidic enough (likely a $\mathrm{pH}$ much greater than 2.5) to induce chemical pneumonitis. Bacterial load introduced from the oral cavity or upper gastrointestinal tract is normally nonvirulent and are usually anaerobic organisms, capable of inducing lung infections due to their large volume [6,9]. However, despite attempts for a more clear-cut classification, there is still confusion surrounding the terminology and the precise definition [10].

\section{INCIDENCE AND EPIDEMIOLOGY}

Gastric aspiration is a known complication of general anesthesia with an incidence of one in every 2,000-30,000 cases [11,12]. Moreover, it has been recently estimated that aspiration occurs roughly in 3 every 10,000 anes- thetic procedures, with higher frequency in special populations and emergency situations [13]. Dental treatment for disabled or handicapped patients often requires general anesthesia or sedation due to the patients' inability to cooperate with the procedure. These patients often have general medical issues along with dental problems such as poor oral hygiene, and consequently a higher chance of anesthetic complications, particularly aspiration-related $[14,15]$. One study reported aspiration pneumonia in $12(9.8 \%)$ out of 123 elderly patients (> $65 \mathrm{y}$ old) who survived cardiovascular surgery and final extubation [16]. Moreover, aspiration frequently occurs in ICU patients, elderly, and nursing home residents $[17,18]$. A case-control study on nursing home-acquired pneumonia patients and community-acquired pneumonia patients has reported an incidence rate of $18 \%$ and $5 \%$, respectively [19].

However, most cases of aspiration events are either silent or unwitnessed; accordingly, the true incidence rate of aspiration-induced lung injury is difficult to estimate. A prospective study that used the bronchoalveolar lavage level of pepsin as a surrogate marker of aspiration in ICU patients has reported that $88.9 \%$ of the patients had at least one aspiration event [20]. Unwitnessed gastric aspiration is thought to be important to explain many cases of perioperative pulmonary dysfunction. However, most aspiration pneumonitis cases are often misdiagnosed as bacterial pneumonia, whereby the patients are consequently given the inappropriate treatment $[5,18]$.

The severity of the lung injury after aspiration differs 
based on the content, amount, and acidity of the aspirate, as well as certain characteristics of the patients (i.e. oropharyngeal colonization or host defense mechanisms); it also varies widely from mild and subclinical pneumonitis to progressive respiratory failure. In a retrospective study on patients who underwent general anesthesia, Warner et al. [12] have reported a total of 66 patients who had aspiration, out of which 42 were asymptomatic, 13 required mechanical ventilation for more than 6 hours, and 3 patients died. Gastric aspiration is a direct key cause of severe ARDS [21,22]. More severe and persistent ARDS occurs in about $1 / 3$ of the aspiration pneumonitis patients $[23,24]$. The incidence of ARDS in the United States varies between $50,000-150,000$ cases per year [21, 25-30].

\section{PATHOPHYSIOLOGY}

Aspiration pneumonitis and aspiration pneumonia are clinically difficult to distinguish. Although there is some degree of overlap, the two aspiration syndromes are separate disease entities with distinguishable pathophysiology.

First, aspiration pneumonitis is an acute lung injury caused by macroaspiration of refluxed gastric contents. Since 1946, when Mendelson described aspiration pneumonitis as the Mendelson's syndrome, the importance of acid has been emphasized [31]. Mendelson demonstrated that severe pneumonitis induced by acidic gastric contents in the rabbit's lung was comparable to the same condition induced by the same amount of $0.1 \mathrm{~N}$ hydrochloric acid. Subsequently, a study using adult rats has shown that the aspiration of diluted hydrochloric acid ( $\mathrm{pH} 1.25)$ resulted in a characteristic biphasic response against lung injury [32]. The first phase was a direct, corrosive effect of low $\mathrm{pH}$ on the airway's epithelium, with a peak timing of 1-2 hours after acid aspiration. The second phase was a neutrophilic inflammatory response, which occurred 4-6 hours after aspiration. The mechanism of lung injury after acid aspiration involves inflammatory mediators, inflam- matory cells, adhesion molecules, tumor necrosis factor $\alpha$, interleukin-8, enzymes (cyclooxygenase, lipooxygenase), and reactive oxygen species. Among these factors, neutrophils and complement play pivotal roles [33-39].

Gastric contents include not only acid but also food particles. Animal experiments on lung injury by gastric food particles have used small non-acidified gastric particles (SNAP) obtained by washing, filtration, autoclaving, and centrifugation of the stomach contents from rodents [40-42]. Acute neutrophilic inflammation was observed 4-6 hours after tracheal instillation of SNAP. However, in contrast to the acid model, a direct injury in the early stages was not observed [40].

The combined acid and small non-acidified gastric food particles, known as the CASP model (acid + SNAP), closely resembles the actual gastric aspiration. Lung injury due to CASP aspiration was more severe compared with lung injuries due to acid or SNAP alone, in both rats and mice [43-45]. In the CASP model, the bronchoalveolar lavage level of albumin - an index for loss of alveolar-capillary integrity - was significantly increased compared with the acid or SNAP models. Moreover, the ratio of the arterial oxygen partial pressure to fractional inspired oxygen $\left(\mathrm{PaO}_{2} / \mathrm{FIO}_{2}\right)$ ratio, which reflects arterial oxygenation, was significantly lower compared with the other two models [41].

Gastric contents are sterile under normal conditions. However, changes in gastric $\mathrm{pH}$ to inhibit bacterial growth through use of antacids, $\mathrm{H}_{2}$-receptor antagonists, or proton-pump inhibitors can result in an environment where potentially pathogenic organisms become viable $[46,47]$. Furthermore, gastric colonization due to gramnegative bacteria can occur in patients under enteral feeding or patients with gastroparesis or small-bowel obstruction [47-49]. If gastric aspiration occurs under these conditions, lung infection from bacterial load in gastric contents can occur in addition to the acute inflammation due to acid or food particles; this is the case explaining overlap with aspiration pneumonia.

Aspiration pneumonia often occurs after aspiration of colonized oropharyngeal material. It can also occur when 
gastric aspiration occurs subsequently to gastric colonization. If the bacterial burden included in the oropharyngeal secretion is small, and the host defense mechanisms such as coughing, active ciliary clearance, and humoral and cellular immune system are intact, aspiration may not result in lung infection. However, if mechanical, humoral, and cellular defense mechanisms are impaired and the volume of aspirate is sufficiently abundant, aspiration pneumonia can occur [5]. Factors that increase the risk of oropharyngeal colonization of potentially pathogenic organisms and growth of bacterial load in consequently increase the risk of aspiration pneumonia. Indeed, the risk of aspiration pneumonia is low in patients without teeth [50] and in patients under aggressive oral care [51].

Bacteriology is important in explaining the unique pathogenesis of aspiration pneumonia. Compared to previous studies that suggested the anaerobic bacteria as the key pathogen of aspiration-induced lung infection [52-54], recent studies have demonstrated a reduced role of anaerobes not only in aspiration pneumonia but also in lung abscess or empyema [55-59]. The discrepancies may be due to the difference in timing and method of obtaining the microbiologic specimens, as well as the patient characteristics. Etiologic bacteria for aspiration pneumonia are now categorized as community-acquired or hospital-acquired, and are similar to communityacquired pneumonia or hospital-acquired pneumonia [60]. This result may be reflecting the changes in the pathogenesis. In the past, only bulky aspiration of anaerobic normal flora was a key mechanism, but recent studies suggest that oropharyngeal colonization of pathogenic organisms prior to the aspiration event is thought to be an important step in addition to large-volume aspiration.

\section{RISK FACTORS}

Aspiration is frequently observed in patients with conditions including altered mental status, dysphagia or swallowing dysfunction, esophageal motility disorders, gastrointestinal disorders, and enteral tube feeding.
Predisposing conditions of aspiration-induced lung injury are undoubtedly related to risk factors such as frequent and/or large-volume aspiration and oropharyngeal or gastric colonization that provide the infection source. However, it is difficult to derive a comprehensive conclusion on independent factors that are directly linked to aspiration pneumonitis or aspiration pneumonia. This is due to multiple reasons including the inconsistent use of terms related to aspiration, i.e., aspiration pneumonitis and aspiration pneumonia among different studies, patient demographics that can act as an uncontrollable confounding factor, and presence of comorbidity [61,62]. However, special care for the patients with risk factors of aspiration is undoubtedly needed to prevent aspiration-induced lung injury.

Adnet and Baud [63] have reported that the risk of aspiration increases with the degree of unconsciousness measured using Glasgow coma scale. Aspiration pneumonitis is associated with acute unconsciousness from sedation, poisoning, or trauma [31,64]. Vomiting and large-volume reflux of gastric contents, which frequently occur in unconscious patients, are likely to increase the risk of aspiration pneumonia.

Dysphagia is a complication associated with neurologic diseases such as dementia, Parkinson's disease, multiple sclerosis, and stroke. Dysphagia increases the aspiration risk of oropharyngeal contents and is associated more closely with aspiration pneumonia than with chemical pneumonitis based on the pathophysiology $[9,65]$. The swallowing mechanism is also affected by the anatomy of the chest. Swallowing dysfunction is frequently observed in patients with a hyperinflated chest anatomy due to the chronic obstructive pulmonary disease (COPD). Previously, patients with COPD displayed defects in the laryngeal elevation during swallowing compared with controls, necessitating the use of protective swallowing strategies [66]. It has been recently reported in nursing home residents and post-stroke populations that COPD is a risk factor for aspiration pneumonia $[62,67]$. Other common risk factors of frequent or large-volume aspiration are outlined in Table 2. 
Table 2. Risk factors for frequent or large volume aspiration

\begin{tabular}{lc}
\hline Altered mental status & Dysphagia or swallowing dysfunction \\
Sedation & Dementia \\
Poisoning & Parkinson's disease \\
Traumatic brain injury & Stroke \\
Seizure disorder & Chronic obstructive pulmonary disease \\
Gastrointestinal disorders & Esophageal motility disorders \\
Gastroesophageal reflux & Primary \\
Gastroparesis & Achalasia \\
Bowel obstruction/ileus & Esophageal stricture \\
Interventional factors & Secondary \\
Presence of endotracheal tube & Scleroderma \\
Enteral tube feeding & Polymyositis \\
\hline
\end{tabular}

In addition to the aspiration risk factors, microbiologic factors affect the occurrence risk of aspiration pneumonia, which increases depending on the number of microbes in the oropharyngeal or gastric aspirate and virulence. Previous studies have suggested that factors related to oral hygiene are associated with the occurrence of pneumonia $[68,69]$. Dental or gingival diseases increase the oral microbial density and virulence. Consequently, the occurrence risk of pneumonia increases when aspiration occurs. Terpenning et al. [68] have analyzed the dental and oral risk factors associated with aspiration pneumonia incidence along with other medical risk factors. They identified the dental decay, presence of cariogenic bacteria, and periodontal pathogens as significant risk factors. One study observed oral cavities of elderly patients requiring long term care who contract aspiration pneumonia and described characteristic change like mucous membranes residues like oblate, coated tongue, or remaining roots after losing the crown portion. These factors were also suggested as environmental factors that induce colonization of bacterial flora, which are not observed under healthy oral conditions [70]. Proton pump inhibitors and histamine receptor- 2 antagonists change the acidic gastric environment and promote gastric colonization. Although these drugs do not increase the risk of gastric aspiration, they are strongly association with pneumonia [71,72].

\section{DIAGNOSIS}

Patients with risk factors for aspiration can be suspected of having aspiration in case they show acute symptoms such as coughing, choking, shortness of breath, cyanosis, tachypnea, tachycardia, speaking difficulty, and hoarseness [2]. Witnessed aspiration is evident by validating the presence of oral contents, food particles, pepsin, or bile in the trachea-bronchial tree or bronchoalveolar lavage fluid. In patients with severe trauma, bloodcontaining aspirates can be observed [73]. Following aspiration, if patients show acute inflammatory signs, such as fever, tachycardia, tachypnea, and leukocytosis, or respiratory symptoms/signs, such as cough, sputum, and hypoxia, combined with new or worsened infiltrates that can be observed on a chest radiograph, they may be suffering from an aspiration-induced lung injury. Moreover, patients are diagnosed with either aspiration pneumonia or aspiration pneumonitis with subsequent bacterial infection in case of a bacteriologic evidence of an infection. Patients with aspiration pneumonitis or pneumonia may progress to acute lung injury and acute respiratory distress symptom (ALI/ARDS), which is characterized by hypoxemia and respiratory failure. Thus, the work of breathing increases and lung compliance decreases, leading to pulmonary hypertension or cor pulmonale [2].

However, one of the reasons for difficult diagnosis is unwitnessed aspiration or silent (asymptomatic) aspira- 
Table 3. Comparison between aspiration pneumonitis and aspiration pneumonia

\begin{tabular}{|c|c|c|}
\hline & Aspiration pneumonitis & Aspiration pneumonia \\
\hline Primary mechanism & Aspiration of sterile gastric contents & Aspiration of colonized oropharyngeal material \\
\hline Pathophysiology & Acute lung injury from acidic and particulate gastric material & $\begin{array}{l}\text { Acute pulmonary inflammatory response to bacteria and } \\
\text { bacterial products }\end{array}$ \\
\hline Bacteriologic finding & Initially sterile, with subsequent bacterial infection possible & Gram-positive, gram-negative rods, and (rarely) anaerobes \\
\hline Main risk factors & Depressed level of consciousness & Dysphagia and gastric dysmotility \\
\hline Aspiration event & May be witnessed & Usually not witnessed \\
\hline Typical presentation & $\begin{array}{l}\text { Patient with depressed level of consciousness in whom a } \\
\text { pulmonary infiltrate and respiratory symptoms develop }\end{array}$ & $\begin{array}{l}\text { Institutionalized patient with dysphasia in whom clinical } \\
\text { feature of pneumonia and an infiltrate in a dependent } \\
\text { bronchopulmonary segment develop }\end{array}$ \\
\hline
\end{tabular}

tion. If lung injury is suspected without clear evidence of prior aspiration, the clinician is required to make a diagnosis by exclusion. Patients can be diagnosed with aspiration-induced lung injury if they exhibit risk factors for aspiration only after excluding other possible causes of hypoxia, such as pulmonary edema, pulmonary embolism, and community- or hospital-acquired pneumonia. Such diagnosis is possible if patients show radiographic evidence of infiltrate in dependent bronchopulmonary segment $[5,74]$. When the patient is in a recumbent position, the dependent pulmonary segments are the posterior segments of the upper lobes and apical segments of the lower lobes. During walking or in a semirecumbent position, the basal segments of lower lobes are mainly involved [5,75].

Another challenge is to distinguish between aspiration pneumonitis and aspiration pneumonia. Clinical features assist in differentiating these two entities. Unlike aspiration pneumonitis, the aspiration event is not frequently witnessed in aspiration pneumonia [5,75]. If aspiration as a preceding event is not obvious, the patient is more likely to have aspiration pneumonia. A large volume of stomach contents is needed to induce chemical pneumonitis, resulting in a more evident aspiration events in cases of aspiration pneumonitis. Furthermore, the clinical course of aspiration pneumonitis is more rapidly progressing; hyper-acute hypoxemia occurs, and devastating lung injury can occur and be resolved within 48 hours. These patients are likely to exhibit symptoms such as bronchospasm, frothy sputum, and bilateral patchy infiltrates, even in nondependent lung fields [5,75]. Features that differ between aspiration pneumonitis and aspiration pneumonia are outlined in Table 3 .

However, there is no gold standard to differentiate between these two entities. Due to these difficulties, there have been attempts to use biomarkers. El-Solh et al. [76] have reported the use of serum procalcitonin levels to distinguish between aspiration pneumonia and aspiration pneumonitis. Indeed, the serum concentration of procalcitonin increases under various bacterial and viral infections [77]. However, no significant differences in procalcitonin levels were observed between the negativeculture-group and the positive-culture-group of bronchoalveolar lavage fluid.

\section{TREATMENT}

The main principle of treatment is that immediate cares based on the symptomatology and progression of the disease is essential prior to any efforts to differentiate between aspiration pneumonitis and pneumonia. However, the direction of the treatment is different for the two conditions and consists of supportive management itself for aspiration pneumonitis and antimicrobial therapy for aspiration pneumonia [74].

If aspiration is witnessed or suspected, the patient's position should be adjusted to minimize the risk of additional aspiration. For conscious patients, the head should be rotated laterally, and suction is applied to the oral and pharyngeal cavities [78]. Humidified oxygen should be administered and nebulized bronchodilator is used if necessary. Furthermore, the head of bed is raised by 45 degrees. Indications for intubation are similar to 
the general indications based on the general neurologic status, degree of hypoxia, and hemodynamic stability. To facilitate bronchoscopy in large volume solid aspiration, intubation is preferred [78,79]. Mechanical ventilation should be provided using the lung protective strategy. To prevent recurrent aspiration, a nasogastric tube is inserted and gastric decompression is performed through either suction or gravity drainage. Quantitative bacteriology using a bronchoalveolar lavage sample obtained through bronchoscopy not only serves as a guide for definitive therapy and de-escalation of antibiotics but can also aid decisions on whether antibiotics should be discontinued if there is no significant bacterial growth [80].

In aspiration pneumonitis, antibiotic therapy is not necessary. However, since it is difficult to distinguish between pneumonitis and pneumonia, it is common practice to use antibiotics with the potential for aspiration pneumonia in mind. In a 2001 survey, the majority of intensivists prescribed antibiotics to patients suspected of aspiration, and $72.4 \%$ chose empirical antibiotic regimen over a pathogen specific regimen [81]. The choice of antibiotics can vary based on the local ecology of the ICU. However, it is considered adequate to start with early, empiric, and broad-spectrum antibiotics [82]. Subsequently, during the next 72 hours, the use of antibiotics is de-escalated based on definitive and quantitative culture. In case no significant bacterial growth is observed in the culture, the antibiotics are then discontinued. Based on the bacteriological trend, the use of antibiotics for anaerobic coverage is unnecessary. However, in cases of severe periodontal diseases or evidence of necrotizing pneumonia or lung abscess in computed tomography, the use of antibiotics with anaerobic coverage can be considered $[60,83]$.

\section{PREVENTION}

Despite proper treatment, aspiration pneumonitis and aspiration pneumonia exhibit high morbidity and mortality; therefore, prevention is crucial. The primary purposes of prevention, for patients with risk factors of aspiration, are to reduce the frequency and amount of aspiration and to minimize the colonization of pathogenic organisms.

General anesthesia is a key risk factor of gastric aspiration, and an opportunity for proactive management and prevention. Fasting prior to the surgery or procedure is one of the key preventive measures to avoid gastric aspiration during general anesthesia. The period of fasting is typically 8 hours as recommended by the American Society of Anesthesiologists (ASA). However, for clear liquids, fasting for longer than $2 \mathrm{~h}$ has not shown additional benefits in lowering the risk $[84,85]$. Based on these facts, ASA recommends 2-h fasting for clear liquids for patients of all age groups. The role of fasting when performing sedation for procedures in the emergency department (ED) is controversial. This is because the risk of aspiration during sedation for procedures in ED is thought to be very low, and ED patients are typically healthy without preparation for fasting prior to the admission [86]. Nevertheless, when performing sedation for the procedure, preventive measures, such as adjusting the sedation depth, identifying high risk patients, and monitoring during the procedure, must be considered. The most important intervention to prevent aspiration in inpatients and ICU patients is to position the patients in a semi-recumbent position. Using radioactively labeled gastric contents, it has been found that positioning patients under mechanical ventilation into a semirecumbent position results in a reduced rate of reflux, thus mitigating the risk of aspiration $[87,88]$. Indeed, the frequency of aspiration was higher in patients in supine position, while the frequency was dependent on the duration of the supine position. In a clinical study comparing the occurrence rate of nosocomial pneumonia in patients under mechanical ventilation, it has been observed that the patient group in semi-recumbent position had significantly lower occurrence rate compared with the patient group in supine position. Furthermore, the difference was more definite in patients receiving enteral feeding [89]. Currently, the semi-recumbent position is a standard practice to prevent aspiration and associated complications. 
Dietary intervention has been attempted in patients with dysphasia. The occurrence rate of aspiration pneumonia has been reported to be lower in pseudobulbar dysphagia patients that received mechanical diet with thickened liquids compared with the patients that received pureed diet with thin liquids [90]. However, the occurrence rate of pneumonia was comparable among post-stroke patient groups who were divided into three randomized groups depending on the degree of dietary intervention by a dysphagia therapist [91].

Given that enteric tube feeding increases the risk of aspiration, several attempts have been made to compare different forms of tube feeding to minimize the risk. The most relevant comparison was between gastric and postpyloric feeding. When considering gastric dysmotility due to a critical illness, gastroparesis, or medication, the postpyloric feed was thought to be a superior option [92]. However, two randomized prospective clinical studies have reported no difference in the aspiration rates between the two feeding types [93,94]. In terms of efficiency to reach the nutritional goal, post-pyloric feed has been considered superior to gastric feeding $[95,96]$. Previous randomized clinical trials have reported no difference in pneumonia complication rate between the nasogastric tube feed and the percutaneous endoscopic gastrostomy tube feed $[97,98]$.

Poor oral hygiene increases the risk of aspiration pneumonia. Therefore, oral health care can help prevent aspiration pneumonia by reducing the risk. Currently, the concept of oral health care includes not only oral cleaning but also eating function training. Through oral hygiene management, including oral moisture retention and mechanical cleaning of the tongue and palate, the bacterial burden can be minimized. And improving eating function reduces the occurrence rate of large-volume aspiration [70].

\section{CONCLUSION}

Aspiration pneumonitis and pneumonia are acute pulmonary diseases that occur following macroaspiration. Distinguishable characteristics from other aspiration syndromes include rapid progression after large volume aspiration. Although these two diseases are difficult to distinguish clinically, they are two independent disease entities with characteristic pathophysiology. Aspiration pneumonitis is a lung injury from acute inflammation that occurs after chemical burns in the airways and lung parenchyma, while aspiration pneumonia is a pulmonary infection from large-volume aspiration of an infection source. When respiratory or systemic symptoms are observed, supportive care for different symptoms must be immediately provided. Treatment with early, empiric, broad-spectrum antibiotics should be administered then selection of pathogen specific antibiotics or decision to stop or continue the use of antibiotics is made based on quantitative bacteriology.

NOTES: There are no financial or other issues that might lead to conflict of interest.

\section{REFERENCES}

1. Venes D. Taber's cyclopedic medical dictionary. Edited by, FA Davis. 2013.

2. Zaloga GP. Aspiration-related illnesses: Definitions and diagnosis. JPEN J Parenter Enteral Nutr 2002; 26: S2-S8.

3. Huxley EJ, Viroslav J, Gray WR, Pierce AK. Pharyngeal aspiration in normal adults and patients with depressed consciousness. Am J Med 1978; 64: 564-8.

4. DiBardino DM, Wunderink RG. Aspiration pneumonia: A review of modern trends. J Crit Care 2015; 30: 40-8.

5. Marik PE. Aspiration pneumonitis and aspiration pneumonia. N Engl J Med 2001; 344: 665-71.

6. Teabeaut JR 2nd. Aspiration of gastric contents: An experimental study. Am J Pathol 1952; 28: 51-7.

7. Cameron JL, Sebor J, Anderson RP, Zuidema GD. Aspiration pneumonia: Results of treatment by positivepressure ventilation in dogs. J Surg Res 1968; 8: 447-57. 
8. Cameron JL, Caldini P, Toung JK, Zuidema GD. Aspiration pneumonia: Physiologic data following experimental aspiration. Surgery 1972; 72: 238-45.

9. Marik PE, Kaplan D. Aspiration pneumonia and dysphagia in the elderly. Chest 2003; 124: 328-36.

10. Japanese Respiratory Society. Aspiration pneumonia. Respirology 2009; 14: S59-64.

11. Olsson GL, Hallen B, Hambraeus-Jonzon K. Aspiration during anaesthesia: A computeraided study of 185358 anaesthetics. Acta Anaesthesiol Scand 1986; 30: 84-92.

12. Warner MA, Warner ME, Weber JG. Clinical significance of pulmonary aspiration during the perioperative period. Anesthesiology 1993; 78: 56-62.

13. Abdulla S. Pulmonary aspiration in perioperative medicine. Acta Anaesthesiol Belg 2013; 64: 1-13.

14. Seo KS, Chang J, Shin TJ, Yi YE, Kim HJ. Pneumonia after dental treatment under ambulatory general anesthesia in mentally retard patient: A case report. J Korean Dent Soc Anesthesiol 2008; 8: 122-6.

15. Seo KS, Jang KT, Kim HJ, Yum KW. The status of comprehensive dental treatment and type of disabilities of the patients treated under outpatient general anesthesia at the clinic for the disabled in seoul national university dental hospital. J Korean Dent Soc Anesthesiol 2006; 6: $82-8$.

16. Miyata E, Tanaka A, Emori H, Taruya A, Miyai S, Sakagoshi $\mathrm{N}$. Incidence and risk factors for aspiration pneumonia after cardiovascular surgery in elderly patients. Gen Thorac Cardiovasc Surg 2016; 65: 96-101.

17. Mylotte JM, Naughton B, Saludades C, Maszarovics Z. Validation and application of the pneumonia prognosis index to nursing home residents with pneumonia. J Am Geriatr Soc 1998; 46: 1538-44.

18. Mylotte JM, Goodnough S, Naughton BJ. Pneumonia versus aspiration pneumonitis in nursing home residents: Diagnosis and management. J Am Geriatr Soc 2003; 51: $17-23$.

19. Marrie TJ, Durant H, Kwan C. Nursing home-acquired pneumonia: A case-control study. J Am Geriatr Soc 1986; 34: $697-702$

20. Metheny NA, Clouse RE, Chang Y-H, Stewart BJ, Oliver
DA, Kollef MH. Tracheobronchial aspiration of gastric contents in critically ill tube-fed patients: Frequency, outcomes, and risk factors. Crit Care Med 2006; 34: 1007-15.

21. Ware LB, Matthay MA. The acute respiratory distress syndrome. N Engl J Med 2000; 342: 1334-49.

22. Raghavendran K, Davidson BA, Helinski JD, Marschke CJ, Manderscheid P, Woytash JA, et al. A rat model for isolated bilateral lung contusion from blunt chest trauma. Anesth Analg 2005; 101: 1482-9.

23. Fowler AA, Hamman RF, Good JT, Benson KN, Baird M, Eberle DJ, et al. Adult respiratory distress syndrome: Risk with common predispositions. Ann intern med 1983; 98: 593-7.

24. Pepe PE, Potkin RT, Reus DH, Hudson LD, Carrico CJ. Clinical predictors of the adult respiratory distress syndrome. Am J Surg 1982; 144: 124-30.

25. Hudson LD, Milberg JA, Anardi D, Maunder RJ. Clinical risks for development of the acute respiratory distress syndrome. Am J Respir Crit Care Med 1995; 151: 293-301.

26. Bernard GR, Artigas A, Brigham KL, Carlet J, Falke K, Hudson L, et al. Report of the american-european consensus conference on ARDS: Definitions, mechanisms, relevant outcomes and clinical trial coordination. Intensive Care Med 1994; 20: 225-32.

27. Doyle RL, Szaflarski N, Modin GW, Wiener-Kronish JP, Matthay MA. Identification of patients with acute lung injury. Predictors of mortality. Am J Respir Crit Care Med 1995; 152: 1818-24.

28. Rubenfeld GD. Epidemiology of acute lung injury. Crit Care Med 2003; 31: S276.

29. Goss CH, Brower RG, Hudson LD, Rubenfeld GD, ARDS Network. Incidence of acute lung injury in the united states. Crit Care Med 2003; 31: 1607-11.

30. Treggiari MM, Hudson LD, Martin DP, Weiss NS, Caldwell E, Rubenfeld G. Effect of acute lung injury and acute respiratory distress syndrome on outcome in critically ill trauma patients. Crit Care Med 2004; 32: 327-31.

31. Mendelson CL. The aspiration of stomach contents into the lungs during obstetric anesthesia. Obstet Gynecol Surv 1946; 1: 837-9. 
32. Kennedy TP, Johnson KJ, Kunkel RG, Ward PA, Knight PR, Finch JS. Acute acid aspiration lung injury in the rat: Biphasic pathogenesis. Anesth Analg 1989; 69: 87-92.

33. Nader-Djalal N, Knight PR 3rd, Thusu K, Davidson BA, Holm BA, Johnson KJ, et al. Reactive oxygen species contribute to oxygen-related lung injury after acid aspiration. Anesth Analg 1998; 87: 127-33.

34. Folkesson HG, Matthay MA, Hebert CA, Broaddus VC. Acid aspiration-induced lung injury in rabbits is mediated by interleukin-8-dependent mechanisms. J Clin Invest 1995; 96: 107-16.

35. Goldman G, Welbourn R, Kobzik L, Valeri CR, Shepro D, Hechtman HB. Synergism between leukotriene B4 and thromboxane A2 in mediating acid-aspiration injury. Surgery 1992; 111: 55-61.

36. Goldman G, Welbourn R, Kobzik L, Valeri CR, Shepro D, Hechtman HB. Tumor necrosis factor-alpha mediates acid aspiration-induced systemic organ injury. Ann Surg 1990; 212: 513-9; discussion 9-20.

37. Nagase T, Ohga E, Sudo E, Katayama H, Uejima Y, Matsuse $\mathrm{T}$, et al. Intercellular adhesion molecule-1 mediates acid aspiration-induced lung injury. Am J Respir Crit Care Med 1996; 154: 504-10.

38. Weiser MR, Pechet TT, Williams JP, Ma M, Frenette PS, Moore FD, et al. Experimental murine acid aspiration injury is mediated by neutrophils and the alternative complement pathway. J Appl Physiol 1997; 83: 1090-5.

39. Knight PR, Druskovich G, Tait AR, Johnson KJ. The role of neutrophils, oxidants, and proteases in the pathogenesis of acid pulmonary injury. Anesthesiology 1992; 77: $772-8$.

40. Knight PR, Rutter T, Tait AR, Coleman E, Johnson K. Pathogenesis of gastric particulate lung injury: A comparison and interaction with acidic pneumonitis. Anesth Analg 1993; 77: 754-60.

41. Knight PR, Davidson BA, Nader ND, Helinski JD, Marschke CJ, Russo TA, et al. Progressive, severe lung injury secondary to the interaction of insults in gastric aspiration. Exp Lung Res 2004; 30: 535-57.

42. Davidson BA, Knight PR, Wang Z, Chess PR, Holm BA, Russo TA, et al. Surfactant alterations in acute inflamma- tory lung injury from aspiration of acid and gastric particulates. Am J Physiol Lung Cell Mol Physiol 2005; 288: L699-L708.

43. Davidson BA, Knight PR, Helinski JD, Nader ND, Shanley TP, Johnson KJ. The role of tumor necrosis factor- $\alpha$ in the pathogenesis of aspiration pneumonitis in rats. Anesthesiology 1999; 91: 486-99.

44. Manderscheid PA, Bodkin RP, Davidson BA, Jensen E, Russo TA, Knight PR. Bacterial clearance and cytokine profiles in a murine model of postsurgical nosocomial pneumonia. Clin Diagn Lab Immunol 2004; 11: 742-51.

45. Bless NM, Huber-Lang M, Guo R-F, Warner RL, Schmal H, Czermak BJ, et al. Role of CC chemokines (macrophage inflammatory protein-1 $\beta$, monocyte chemoattractant protein-1, RANTES) in acute lung injury in rats. J Immunol 2000; 164: 2650-9.

46. Garvey BM, McCambley JA, Tuxen DV. Effects of gastric alkalization on bacterial colonization in critically ill patients. Crit Care Med 1989; 17: 211-6.

47. Bonten MJ, Gaillard CA, van der Geest S, van Tiel FH, Beysens AJ, Smeets HG, et al. The role of intragastric acidity and stress ulcus prophylaxis on colonization and infection in mechanically ventilated ICU patients. A stratified, randomized, double-blind study of sucralfate versus antacids. Am J Respir Crit Care Med 1995; 152: 1825-34.

48. Spilker CA, Hinthorn DR, Pingleton SK. Intermittent enteral feeding in mechanically ventilated patients: The effect on gastric $\mathrm{pH}$ and gastric cultures. Chest 1996; 110: 243-8.

49. Bonten MJ, Gaillard CA, van Tiel FH, van der Geest S, Stobberingh EE. Continuous enteral feeding counteracts preventive measures for gastric colonization in intensive care unit patients. Crit Care Med 1994; 22: 939-44.

50. Terpenning M, Bretz W, Lopatin D, Langmore S, Dominguez B, Loesche W. Bacterial colonization of saliva and plaque in the elderly. Clin Infect Dis 1993; S314-6.

51. Yoneyama T, Yoshida M, Matsui T, Sasaki H. Oral care and pneumonia. Oral Care Working Group. Lancet 1999; 354: 515.

52. Bartlett JG, Gorbach SL, Finegold SM. The bacteriology of aspiration pneumonia. Am J Med 1974; 56: 202-7. 
53. Cesar L, Gonzalez C, Calia FM. Bacteriologic flora of aspiration-induced pulmonary infections. Arch Intern Med 1975; 135: 711-4.

54. Bartlett JG, Gorbach SL. Treatment of aspiration pneumonia and primary lung abscess: Penicillin g vs clindamycin. JAMA 1975; 234: 935-7.

55. Tokuyasu H, Harada T, Watanabe E, Okazaki R, Touge $\mathrm{H}$, Kawasaki $\mathrm{Y}$, et al. Effectiveness of meropenem for the treatment of aspiration pneumonia in elderly patients. Internal Med 2009; 48: 129-35.

56. El-Solh AA, Pietrantoni C, Bhat A, Aquilina AT, Okada M, Grover V, et al. Microbiology of severe aspiration pneumonia in institutionalized elderly. Am J Respir Crit Care Med 2003; 167: 1650-4.

57. Takayanagi N, Kagiyama N, Ishiguro T, Tokunaga D, Sugita Y. Etiology and outcome of community-acquired lung abscess. Respiration 2010; 80: 98-105.

58. Wang JL, Chen KY, Fang CT, Hsueh PR, Yang PC, Chang SC. Changing bacteriology of adult community-acquired lung abscess in taiwan: Klebsiella pneumoniae versus anaerobes. Clin Infect Dis 2005; 40: 915-22.

59. Lobo LJ, Reed KD, Wunderink RG. Expanded clinical presentation of community-acquired methicillin-resistant staphylococcus aureus pneumonia. Chest 2010; 138: 130-6.

60. Mier L, Dreyfuss D, Darchy B, Lanore J, Djedaini K, Weber $\mathrm{P}$, et al. Is penicillin $\mathrm{g}$ an adequate initial treatment for aspiration pneumonia? Intensive Care Med 1993; 19: 279-84.

61. van der Maarel-Wierink CD, Vanobbergen JN, Bronkhorst EM, Schols JM, de Baat C. Risk factors for aspiration pneumonia in frail older people: A systematic literature review. J Am Med Dir Assoc 2011; 12: 344-54.

62. Langmore SE, Skarupski KA, Park PS, Fries BE. Predictors of aspiration pneumonia in nursing home residents. Dysphagia 2002; 17: 298-307.

63. Adnet F, Baud F. Relation between glasgow coma scale and aspiration pneumonia. Lancet 1996; 348: 123-4.

64. Christ A, Arranto CA, Schindler C, Klima T, Hunziker PR, Siegemund M, et al. Incidence, risk factors, and outcome of aspiration pneumonitis in icu overdose patients. Intensive Care Med 2006; 32: 1423-7.
65. Cabre M, Serra-Prat M, Palomera E, Almirall J, Pallares R, Clavé P. Prevalence and prognostic implications of dysphagia in elderly patients with pneumonia. Age Ageing 2010; 39: 39-45.

66. Mokhlesi B, Logemann JA, Rademaker AW, Stangl CA, Corbridge TC. Oropharyngeal deglutition in stable copd. Chest 2002; 121: 361-9.

67. Masiero S, Pierobon R, Previato C, Gomiero E. Pneumonia in stroke patients with oropharyngeal dysphagia: A sixmonth follow-up study. Neurol Sci 2008; 29: 139-45.

68. Terpenning MS, Taylor GW, Lopatin DE, Kerr CK, Dominguez BL, Loesche WJ. Aspiration pneumonia: Dental and oral risk factors in an older veteran population. J Am Geriatr Soc 2001; 49: 557-63.

69. El-Solh AA, Pietrantoni C, Bhat A, Okada M, Zambon J, Aquilina A, et al. Colonization of dental plaques: A reservoir of respiratory pathogens for hospital-acquired pneumonia in institutionalized elders. Chest 2004; 126: 1575-82.

70. Koichiro U. Preventing aspiration pneumonia by oral health care. Japan Med Assoc J 2011; 54: 39-43.

71. Laheij RJ, Sturkenboom MC, Hassing R-J, Dieleman J, Stricker BH, Jansen JB. Risk of community-acquired pneumonia and use of gastric acid-suppressive drugs. JAMA 2004; 292: 1955-60.

72. Herzig SJ, Howell MD, Ngo LH, Marcantonio ER. Acidsuppressive medication use and the risk for hospitalacquired pneumonia. JAMA 2009; 301: 2120-8.

73. Lockey D, Coats T, Parr M. Aspiration in severe trauma: A prospective study. Anaesthesia 1999; 54: 1097-8.

74. Raghavendran K, Nemzek J, Napolitano LM, Knight PR. Aspiration-induced lung injury. Crit Care Med 2011; 39: 818.

75. Bartlett J, Gorbach S. The triple threat of aspiration pneumonia. Chest 1975; 68: 560-6.

76. El-Solh AA, Vora H, Knight III PR, Porhomayon J. Diagnostic utility of serum procalcitonin levels in pulmonary aspiration syndromes. Crit Care Med 2011; 39: 1251.

77. Assicot M, Bohuon C, Gendrel D, Raymond J, Carsin H, Guilbaud J. High serum procalcitonin concentrations in patients with sepsis and infection. Lancet 1993; 341: 
$515-8$.

78. Moore FA. Treatment of aspiration in intensive care unit patients. JPEN J Parenter Enteral Nutr 2002; 26: S69-S74.

79. Haenel JB, Moore FA, Moore EE, Read RA. Efficacy of selective intrabronchial air insufflation in acute lobar collapse. Am J Surg 1992; 164: 501-5.

80. Kollef MH, Bock KR, Richards RD, Hearns ML. The safety and diagnostic accuracy of minibronchoalveolar lavage in patients with suspected ventilator-associated pneumonia. Ann Intern Med 1995; 122: 743-8.

81. Rebuck JA, Rasmussen JR, Olsen KM. Clinical aspirationrelated practice patterns in the intensive care unit: A physician survey. Crit Care Med 2001; 29: 2239-44.

82. Society AT, America IDSo. Guidelines for the management of adults with hospital-acquired, ventilator-associated, and healthcare-associated pneumonia. Am J Respir Crit Care Med 2005; 171: 388-416.

83. Marik PE, Careau P. The role of anaerobes in patients with ventilator-associated pneumonia and aspiration pneumonia: A prospective study. Chest 1999; 115: 178-83.

84. Ingebo KR, Rayhorn NJ, Hecht RM, Shelton MT, Silber GH, Shub MD. Sedation in children: Adequacy of twohour fasting. J Pediatr 1997; 131: 155-8.

85. Sandhar BK, Goresky GV, Maltby JR, Shaffer EA. Effect of oral liquids and ranitidine on gastric fluid volume and ph in children undergoing outpatient surgery. Anesthesiology 1989; 71: 327-30.

86. Green SM, Krauss B. Pulmonary aspiration risk during emergency department procedural sedation-an examination of the role of fasting and sedation depth. Acad Emerg Med 2002; 9: 35-42.

87. Torres A, Serra-Batlles J, Ros E, Piera C, de la Bellacasa JP, Cobos A, et al. Pulmonary aspiration of gastric contents in patients receiving mechanical ventilation: The effect of body position. Ann Intern Med 1992; 116: 540-3.

88. Orozco-Levi M, Torres A, Ferrer M, Piera C, El-Ebiary M, de la Bellacasa JP, et al. Semirecumbent position protects from pulmonary aspiration but not completely from gastroesophageal reflux in mechanically ventilated patients. Am J Respir Crit Care Med 1995; 152: 1387-90.

89. Drakulovic MB, Torres A, Bauer TT, Nicolas JM, Nogué
S, Ferrer M. Supine body position as a risk factor for nosocomial pneumonia in mechanically ventilated patients: A randomised trial. The Lancet 1999; 354: 1851-8.

90. Groher ME. Bolus management and aspiration pneumonia in patients with pseudobulbar dysphagia. Dysphagia 1987; 1: 215-6.

91. DePippo K, Holas M, Reding M, Mandel F, Lesser M. Dysphagia therapy following stroke a controlled trial. Neurology 1994; 44: 1655-60.

92. Metheny NA, Schallom ME, Edwards SJ. Effect of gastrointestinal motility and feeding tube site on aspiration risk in critically ill patients: A review. Heart Lung 2004; 33: 131-45.

93. Esparza J, Boivin MA, Hartshorne MF, Levy H. Equal aspiration rates in gastrically and transpylorically fed critically ill patients. Intensive care Med 2001; 27: 660-4.

94. Strong RM, Condon SC, Solinger MR, Namihas BN, Ito-Wong LA, Leuty JE. Equal aspiration rates from postpylorus and intragastric-placed small-bore nasoenteric feeding tubes: A randomized, prospective study. JPEN J Parenter Enteral Nutr 1992; 16: 59-63.

95. Montecalvo MA, Steger KA, Farber HW, Smith BF, Dennis RC, Fitzpatrick GF, et al. Nutritional outcome and pneumonia in critical care patients randomized to gastric versus jejunal tube feedings. The Critical Care Research Team. Crit Care Med. 1992; 20: 1377-87.

96. Adams GF, Guest DP, Ciraulo DL, Lewis PL, Hill RC, Barker DE. Maximizing tolerance of enteral nutrition in severely injured trauma patients: A comparison of enteral feedings by means of percutaneous endoscopic gastrostomy versus percutaneous endoscopic gastrojejunostomy. J Trauma Acute Care Surg 2000; 48: 459-65.

97. Gomes Jr CA, Andriolo RB, Bennett C, Lustosa SA, Matos D, Waisberg DR, et al. Percutaneous endoscopic gastrostomy versus nasogastric tube feeding for adults with swallowing disturbances. Cochrane Database Syst Rev 2015;(5):CD008096.

98. Loser C, Aschl G, Hebuterne X, Mathus-Vliegen E, Muscaritoli M, Niv Y, et al. Espen guidelines on artificial enteral nutrition-percutaneous endoscopic gastrostomy (peg). Clin Nutr 2005; 24: 848-61. 